\title{
Simple Way: Ensino e Aprendizagem de Engenharia de Software Aplicada através de Ambiente e Projetos Reais
}

\author{
Nadja N. Rodrigues, Naylla V. A. Estrela \\ Instituto Federal de Educação, Ciência e Tecnologia da Paraíba (IFPB) - Campus \\ Cajazeiras - PB - Brasil \\ nadja.rodrigues@ifpb.edu.br, nayllavestrela@gmail.com
}

\begin{abstract}
Understanding the need for integration between academy and industry, this paper reports the use of a software development environment for teaching and learning applied software engineering. The methodology associated to the study was based on the instantiation of real projects of a junior company of Computer Science Area, run through this environment in the classroom. The environment defined roles and activities for the development of projects, as well as templates, procedures and tools for each of its stages. The main contributions of the use of the environment have been the increasing in the project quality and the value added to the students through the use of industry best practices.
\end{abstract}

Resumo. Entendendo a necessidade de integração entre academia e indústria, este artigo relata a utilização de um ambiente de desenvolvimento de software para ensino e aprendizagem de engenharia de software aplicada. A metodologia associada ao estudo baseou-se na instanciação de projetos reais de uma empresa júnior da Área de Ciência da Computação, executados através deste ambiente, em sala de aula. $O$ ambiente definiu papéis e atividades para o desenvolvimento dos projetos, assim como templates, procedimentos e ferramentas para cada uma de suas etapas. As principais contribuições do uso do ambiente foram o aumento na qualidade dos projetos e o valor agregado aos alunos, através do uso das boas práticas da indústria.

\section{Introdução}

Nos dias atuais, é crescente a busca por softwares cada vez mais sofisticados e que produzam os reais resultados esperados, isto é, atendam ou superem as expectativas dos seus stakeholders. Atender a essa demanda com qualidade e assim chegar ao sucesso de um projeto são alguns dos desafios da área de engenharia de software.

Sommerville (2007) explica a engenharia de software como uma disciplina da engenharia que se preocupa com todos os aspectos da produção de software, desde os estágios iniciais de especificação do sistema até a sua manutenção, depois que ele entrou em operação. A engenharia de software é responsável pelas práticas relacionadas ao desenvolvimento de software, sendo formada por um conjunto de métodos, ferramentas e processos para analisar, projetar e desenvolver softwares com qualidade e gerenciar os projetos dentro dos prazos e custos estimados. 
Assim como qualquer processo produtivo, o desenvolvimento de software necessita de uma sistematização que defina os passos, as atividades que serão realizadas e a dependência entre as mesmas, as suas entradas e saídas, os papéis e as responsabilidades de cada um dos atores envolvidos no processo. Para este fim, surgiram os Processos de Desenvolvimento de Software (PDS).

Um PDS é um conjunto de atividades sistematizadas que geram um produto de software, sendo considerado um dos principais mecanismos para se obter software de qualidade e cumprir corretamente os contratos de desenvolvimento. Para Pressman (2006), em um PDS, o problema a ser tratado deve ser dividido em partes menores e, para cada uma delas, uma análise será feita para a busca de soluções.

Quanto à classificação, os PDS se dividem em processos prescritivos (mais burocráticos com relação ao desenvolvimento de software), e não prescritivos (menos burocráticos, ágeis, tentam simplificar o processo de desenvolvimento). Teles (2006) explica que o termo "desenvolvimento tradicional" refere-se aos projetos que se baseiam no desenvolvimento em cascata, sendo o sistema construído linearmente, seguindo uma sequência de fases. Segundo Teles (2006), o “desenvolvimento ágil”, por sua vez, faz referência ao desenvolvimento iterativo, sendo as fases propostas pelo modelo em cascata repetidas diversas vezes durante o projeto.

Cada modelo de desenvolvimento tem suas características definidas conforme com alguns cenários indicados para sua aplicação. As empresas que trabalham com desenvolvimento de software devem desenvolver a visão crítica para entender que esses modelos podem ser utilizados por completo, ou vistos como frameworks de referência para definição dos seus próprios processos de desenvolvimento de software. A decisão de usar, criar ou definir um PDS deve estar diretamente relacionada às características da empresa (tipos de contrato, por exemplo), das suas equipes de desenvolvimento (tamanho da equipe, rotatividade, habilidades, entre outros aspectos), dos seus projetos (tamanho do projeto, entre outros aspectos) e dos seus clientes (exigência de documentação, disponibilidade para apoiar o desenvolvimento, por exemplo).

Entendendo a necessidade de aproximar academia e indústria, e assim despertar a visão crítica dos alunos e prepará-los para a vida prática, apresenta-se uma proposta para ensino de engenharia de software, baseada em um ambiente de desenvolvimento e PDS definidos especificamente para uma empresa júnior que produz softwares.

O presente artigo encontra-se estruturado da seguinte forma: na segunda seção são expostos alguns trabalhos relacionados; a terceira apresenta os principais aspectos da metodologia proposta para ensino de engenharia de software aplicada; na quarta, encontram-se características do ambiente e do PDS utilizado; a quinta relata as informações essenciais sobre o uso desta proposta em meio acadêmico; finalmente, a sexta seção apresenta as considerações finais.

\section{Trabalhos Relacionados}

O ensino de engenharia de software, em ambientes de graduação, tem o objetivo de apresentar aos alunos os diversos aspectos relacionados à construção de sistemas de software, de forma prática. Assim sendo, quanto mais próxima a academia estiver da indústria, mais real será esta experiência para os alunos. 
Acredita-se na dificuldade de utilizar por completo, em ambiente acadêmico, vários dos modelos utilizados na indústria, em virtude das particularidades e diferenças entre esses dois tipos de ambientes. Por outro lado, é imprescindível que os alunos façam uso das boas práticas no desenvolvimento de software e se preparem para o mercado, de acordo com as expectativas das empresas de desenvolvimento.

O cuidado com estes aspectos relacionados ao ensino de engenharia de software pode ser constatado através da literatura que retrata, dentre outros, a criação de metodologias de ensino e PDS próprios para o desenvolvimento de projetos em ambientes acadêmicos. O XP1 [XP1 2007], por exemplo, descreve um PDS que pretende ser útil para alunos que estejam usando um processo de desenvolvimento pela primeira vez, em ambiente universitário. O processo tem as seguintes características: é baseado nas práticas de XP [XP 2011], mas foi idealizado para ser mais simples; pretende abraçar as tarefas imprescindíveis em um processo de software.

Segundo Paiva et al (2004 apud Durscki et al, 2004), o Processo de Produção de Projetos Computacionais Acadêmicos tem como objetivo oferecer um processo de produção de sistemas integrados de software e hardware para o desenvolvimento de projetos no ambiente acadêmico. $\mathrm{O}$ processo permite que seus usuários aumentem seus conhecimentos sobre a utilização de processos e obtenham mais controle sobre a execução de seus projetos. Ademais, propõe a execução de atividades estruturadas e sequenciadas, fazendo uso de modelos (templates) e diagramas de sequência (workflows) definidos, além de apresentar também padrões de documentação.

O YP [YP 2011], por sua vez, é um PDS simplificado que se apóia em práticas do XP, RUP [RUP 2011] e AM [AM 2011], contemplando especialmente os aspectos essenciais de um processo ágil. Segundo Garcia et al (2004), o YP visa auxiliar tanto a gerência do desenvolvimento de aplicações em disciplinas de engenharia de software quanto a aprendizagem dos conceitos desta disciplina na graduação, podendo também ser utilizado em projetos de pequeno e médio porte. Seguem algumas características do YP: ênfase na gerência e na comunicação com o cliente, pontos fortes do processo; não demanda uma grande quantidade de artefatos, apenas o suficiente para manter uma boa gerência; diz apenas quais artefatos devem ser gerados e não como fazê-los, deixando a equipe livre para utilizar a ferramenta que lhe for mais conveniente.

Conforme Paiva et al (2002, apud Paula Filho, 2004), o Processo para Aplicativos Extensíveis Interativos (Praxis) é destinado a dar suporte a projetos didáticos em disciplinas de engenharia de software de cursos de Informática. Algumas características do Praxis: foi elaborado para suportar projetos de 6 meses a 1 ano realizados individualmente ou por pequenas equipes; é baseado em notações de orientação a objetos para análise, projeto e implementação.

O UPEDU [2011] é um conjunto das melhores práticas de engenharia de software, fornecendo orientação para agilizar o trabalho de equipes de desenvolvimento. O UPEDU unifica a equipe e melhora a comunicação. Usando navegação online, cada membro da equipe tem acesso à base de conhecimento do UPEDU, bem como orientações sobre o processo. A base de conhecimentos identifica e atribui responsabilidades, artefatos e tarefas aos membros, de forma que cada um deles possa compreender a sua contribuição para o projeto. A seção de modelos dá acesso a todos os 
modelos de artefatos necessários ao processo de software. A seção de ferramentas fornece uma visão das ferramentas selecionadas para as disciplinas do processo .

Observa-se que o uso de PDS específicos e adaptados aos cenários acadêmicos está se tornando uma prática para ensino de engenharia de software. A expectativa em torno desta estratégia é viabilizar o desenvolvimento de projetos de qualidade, em ambientes acadêmicos, e agregar valor aos alunos, aproximando-os da indústria.

\section{Academia e Empresa: Ensino e Aprendizagem de Engenharia de Software Aplicada através de Ambiente e Projetos Reais}

Considerando a necessidade de aproximar a academia e indústria, através do ensino e aprendizagem de engenharia de software, este trabalho pretende apresentar uma metodologia desenvolvida para fundir o ensino de engenharia de software aplicada em um Curso Superior de Tecnologia em Análise e Desenvolvimento de Sistemas, de uma Instituição de Ensino Superior (IES), com a prática, na empresa júnior formada pelos alunos deste curso, onde os principais produtos gerados são sistemas de software.

A metodologia considerou os seguintes aspectos:

- O desenvolvimento de um PDS que se adequasse à realidade de uma empresa júnior (projetos desenvolvidos por alunos em cursos de graduação) e a aplicação deste PDS em sala de aula. Antes da criação deste PDS, tal empresa trabalhou com outros processos acadêmicos, como o XP1. Entretanto, observou-se que alguns ajustes teriam que ser feitos a este processo, como forma de atender a necessidades específicas da empresa, como ter que manter documentação em virtude da alta rotatividade de alunos na mesma. Assim sendo, optou-se por definir este novo PDS;

- A criação de um ambiente com todos os elementos que compõem o PDS para geração dos projetos da empresa júnior e para ensino e aprendizagem do PDS, nas aulas de engenharia de software aplicada. A estrutura do ambiente baseou-se nas definições do XP1 para tratar os elementos do processo: papéis ("Quem..."), atividades ("O que...”), atividades do tempo (“Quando...”), orientações (“Como...”);

- A utilização de projetos reais da empresa júnior (preferencialmente), ou fíctícios, como estudos de caso nas aulas de engenharia de software aplicada, dadas em forma de oficina de projetos de software;

- A execução do rodízio dos alunos entre os papéis, atividades e artefatos do PDS, de forma que possam passar pelos elementos imprescindíveis à execução do PDS.

\section{Simple Way: Processo e Ambiente de Desenvolvimento de Software}

Esta seção apresenta algumas características do PDS definido para a empresa júnior e do ambiente criado para dar suporte à instanciação dos projetos desta empresa, uma vez que a proposta deste artigo é discutir especialmente a ideia de fazer uso destes enquanto instrumentos para ensino de engenharia de software aplicada.

\subsection{Simple Way Process: Um Processo de Desenvolvimento de Software}

Cada empresa de desenvolvimento de software tem necessidades próprias, de acordo com suas características de trabalho, tipos de projetos desenvolvidos, clientes, dentre 
outras. Para a empresa júnior em estudo, o desenvolvimento de software deve respeitar algumas particularidades da empresa, inerentes a alunos de graduação: alta rotatividade dos integrantes; a equipe não tem o mesmo horário livre em comum; os integrantes da equipe não dispõem de 8 horas diárias de trabalho.

O Simple Way Process (SWP) é um processo de software que se baseia nas boas práticas da engenharia de software e tem como inspiração elementos referentes a cenários de desenvolvimento de software prescritivos ou ágeis, da indústria ou acadêmicos: PMBok [PMBok 2004], Scrum [Scrum 2011], RUP, XP, YP e XP1. Uma das principais características do SWP é ser iterativo e incremental. A ideia desta abordagem consiste em obter, mais rapidamente, feedback do cliente e assim fazer entregas mais rápidas de releases. O SWP divide o desenvolvimento do software em releases (têm duração de 30 dias) e iterações (têm duração de 15 dias).

O SWP sugere os seguintes papéis: gerente de projetos, líderes de grupo (lideram tecnicamente e conduzem parte da equipe), analista, desenvolvedor e testador. Optou-se por diferenciar os papéis em função das habilidades adquiridas pelos alunos ao longo do curso, em diferentes momentos. Acreditou-se que essa abordagem ajudaria a viabilizar a entrada de alunos desde os primeiros até os últimos semestres, proporcionando diferentes tipos de contribuições técnicas à equipe da empresa júnior, e também a cada aluno. Por fim, o papel do cliente também se faz presente.

Para suas atividades, o SWP sugere tanto abordagens baseadas em processos prescritivos como ágeis. A idéia associada a mesclar as abordagens é acomodá-las às necessidades da empresa júnior, como, por exemplo, o fato de ter que manter registros dos projetos bem documentados em virtude da alta rotatividade da equipe, já que o aluno concluinte deve deixar esta empresa. Por outro lado, a necessidade de entregas rápidas, por exemplo, é incompatível com um processo pesado. O SWP pondera esses problemas e tenta equilibrar os aspectos relacionados a eles, buscando alternativas intermediárias para as suas atividades. De forma geral, pode-se dizer que o SWP envolve atividades referentes às seguintes disciplinas: Modelagem de Negócio (ex.: modelar processos de negócio), Requisitos (ex.: gerar diagramas e especificações de casos de uso), Análise e Projeto (ex.: gerar arquitetura e modelos de dados), Implementação (ex.: codificar testes unitários e casos de uso), Testes (ex.: construir roteiros e testes automatizados), Implantação (ex.: construir manual e material de treinamento), Gerência de Projetos (ex.: construir escopo e mapa de riscos, planejar releases e iterações), Gerência de Mudanças (ex.: controlar solicitações de mudança) e Ambiente (ex.: instalação de ferramentas, revisão de templates).

O SWP sugere ainda a ordem de execução dos passos do processo no tempo, além de definir procedimentos (orientações para execução das atividades), templates (modelos dos artefatos gerados pelas atividades) e ferramentas (apóiam a automatização das atividades), de forma a apoiar a sistematização deste processo.

\subsection{Simple Way: Ambiente do Processo}

Para auxiliar a execução das atividades do SWP, foi criado um ambiente com todos os elementos necessários para que os membros da empresa júnior tenham a sua disposição todos os recursos necessários para desenvolver os projetos que usarão o processo. 
De tal modo, para que possa ser acessado de qualquer computador ligado à Internet, o ambiente relacionado ao SWP foi criado através de um site na web (https://sites.google.com/site/simplewayp/), e tem como características principais:

- definição de todos os elementos do processo (especialmente papéis, atividades e artefatos), através de seções como "quem" (papéis do processo), "o que" (atividades do processo), "quando" (execução do processo no tempo), "como" (procedimentos, artefatos e ferramentas do processo);

- informações sobre as referências bibliográficas que orientaram a definição do processo;

- estrutura de navegação planejada para orientar desde os usuários que estão iniciando suas atividades na empresa júnior àqueles que já conhecem o SWP.

A seguir, apresenta-se o ambiente criado para o SWP. Na página "Quem...", o site exibe os papeis do SWP, informações estas que podem ser observadas na Figura 1.

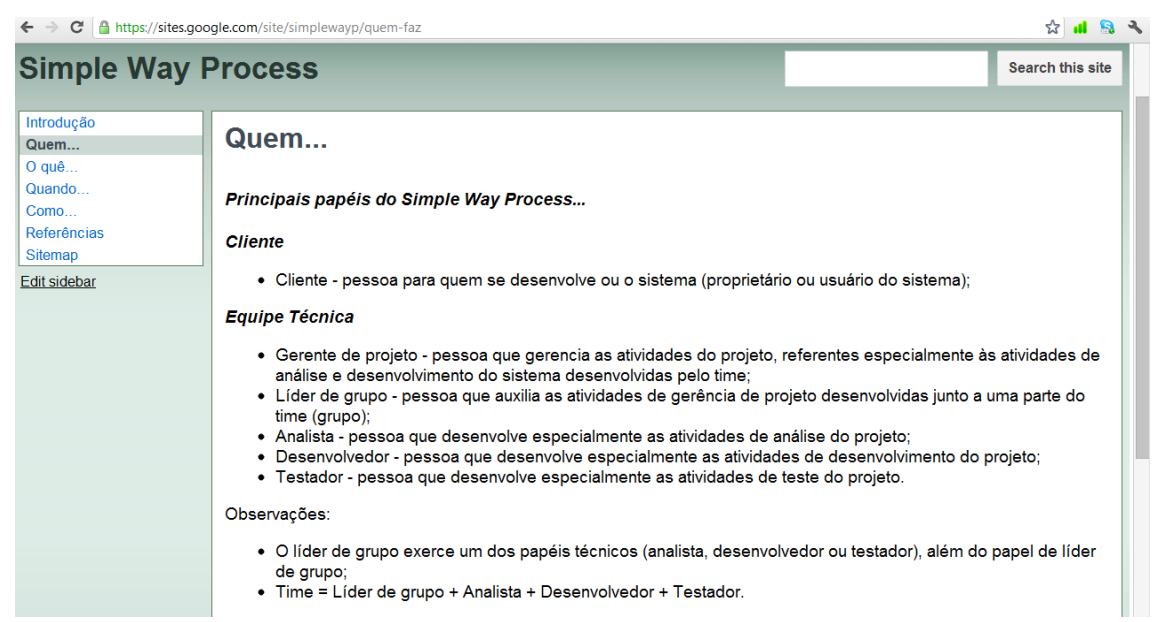

Figura 1. Ambiente do SWP - Página "Quem..."

Na página "O que...", o site expõe as atividades do SWP, as quais podem ser vistas de forma agrupada, por disciplinas ou por papéis, através dos links de navegação específicos. A Figura 2 permite a visualização de tais informações.

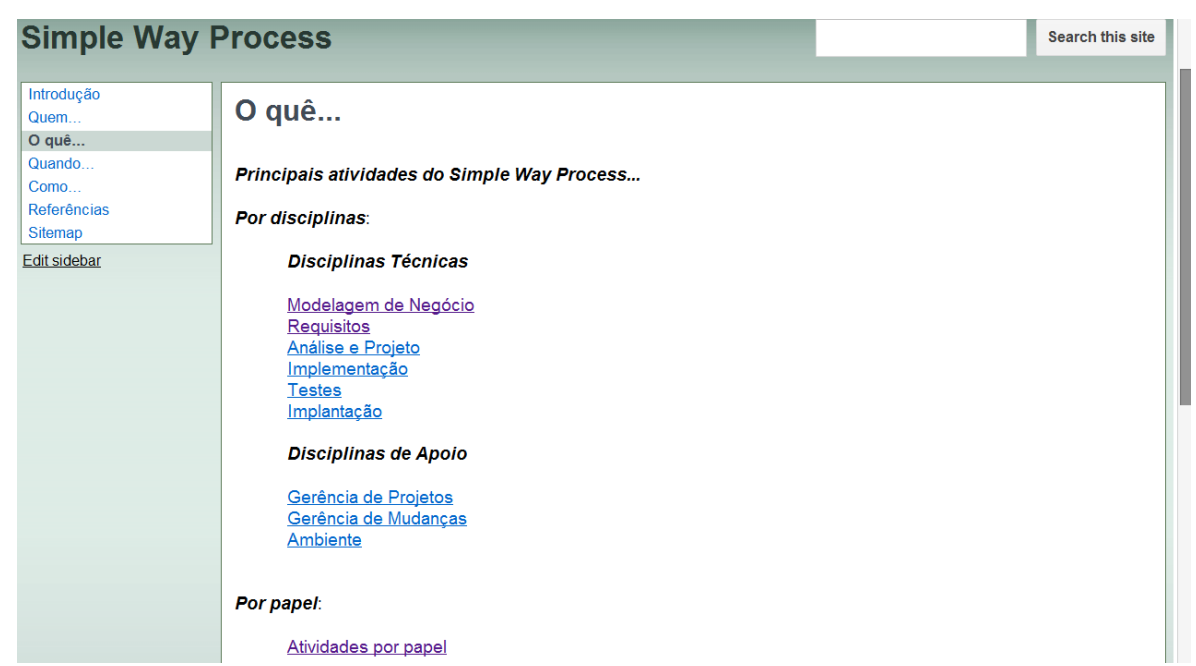

Figura 2. Ambiente do SWP - Página "O quê..." 
A Figura 3 apresenta um exemplo de página que exibe as atividades agrupadas por disciplina. Neste caso, podem ser vistas as atividades da disciplina Modelagem de Negócio, assim como quem executa cada uma delas. Deve ser observado que as informações da coluna responsáveis são links de navegação para a página "Quem...", onde o usuário do site pode consultar informações sobre o papel que executa cada atividade.

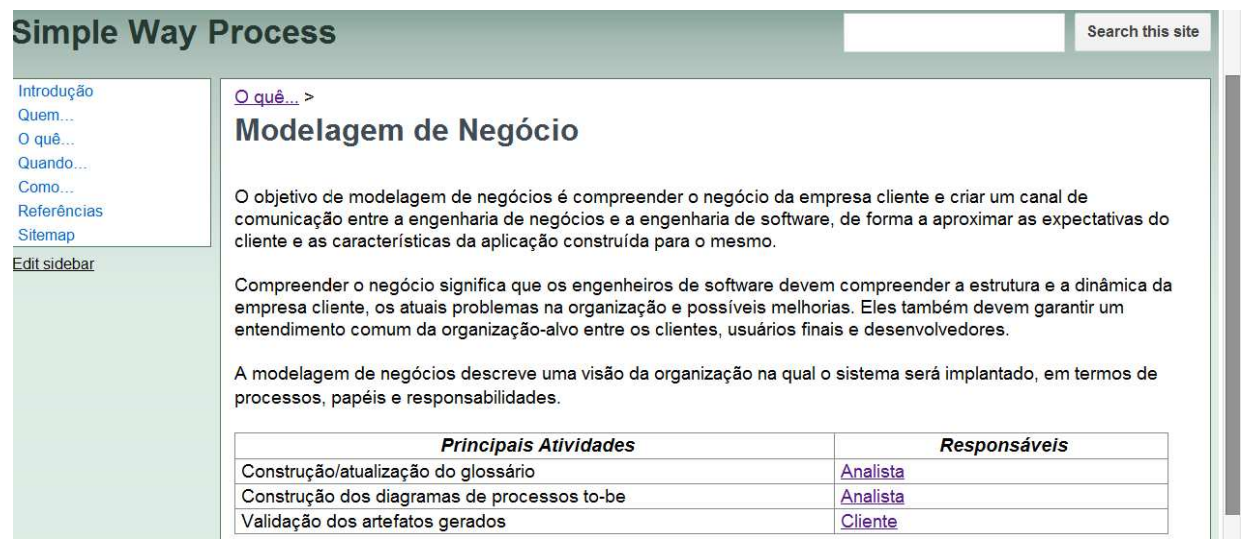

Figura 3. Ambiente SWP - Página "O quê..." - Subpágina Modelagem de Negócio

A Figura 4, por sua vez, oferece um modelo de página que exibe as atividades agrupadas por papel. Nesta opção, verificam-se, portanto, as atividades que cada papel executa. Na referida imagem é possível notar as atividades executadas pelo cliente, além de parte daquelas executadas pelo gerente de projetos. É válido destacar que as informações da coluna papel são links de navegação para a página "Quem...", onde o usuário do site pode consultar informações sobre o papel que executa cada atividade.

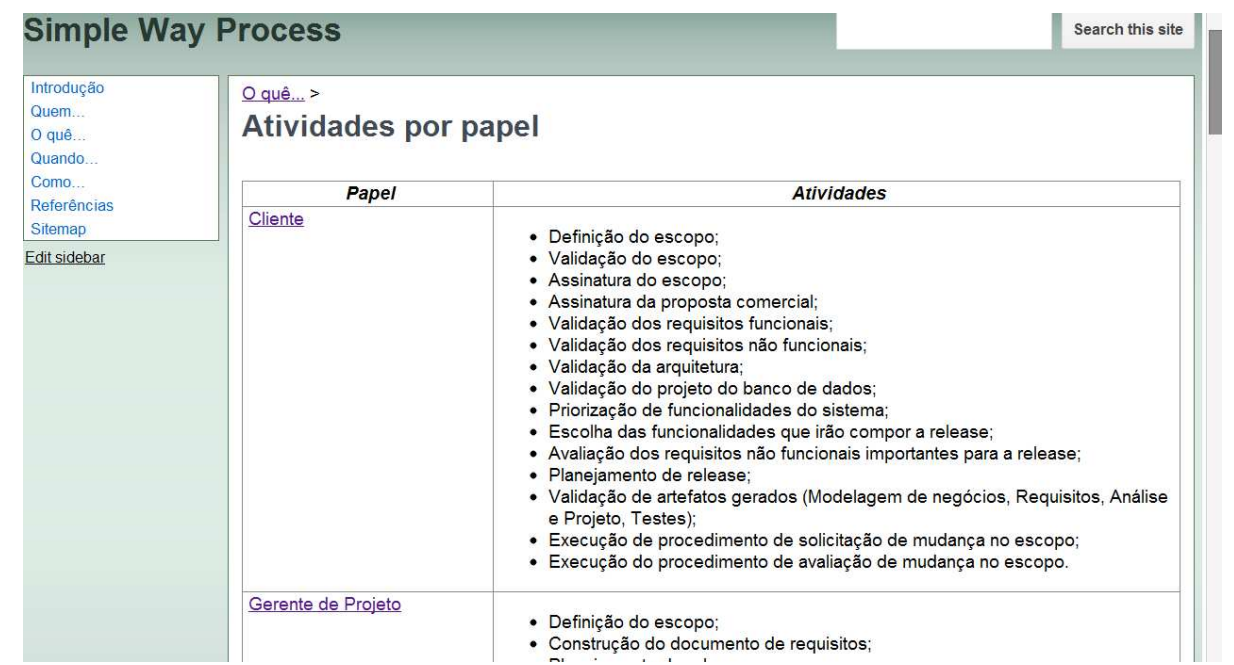

Figura 4. Ambiente SWP - Página "O que..." - Subpágina Atividades por Papel

Na página "Quando...", o site apresenta a execução das atividades do SWP no tempo, como ilustrado na Figura 5. 


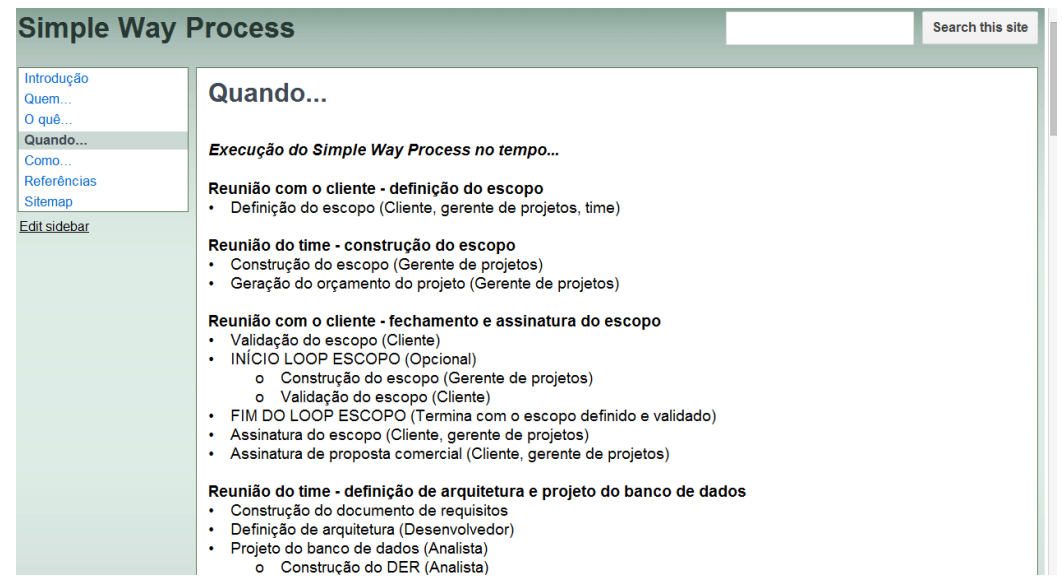

Figura 5 - Ambiente do SWP - Página "Quando..."

Na página "Como...", o site oferece links para as páginas dos procedimentos, templates e ferramentas. Essas informações podem ser vistas na Figura 6.

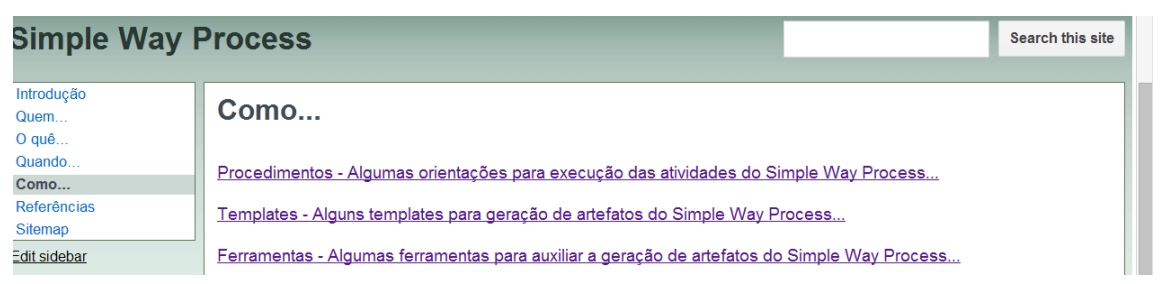

Figura 6 - Ambiente do SWP - Página "Como..."

A Figura 7 apresenta a página que exibe os procedimentos sugeridos para o SWP. É interessante perceber que, em alguns casos, as informações da coluna orientações apresentam links de navegação ou para a página "Templates" (caso a orientação seja a geração de um artefato), ou para a página "Ferramentas" (caso seja necessário o uso de alguma ferramenta para a execução da atividade).

\begin{tabular}{|c|c|c|}
\hline \multicolumn{3}{|c|}{ Simple Way Process } \\
\hline \begin{tabular}{|l|} 
Introdução \\
Quem... \\
O quê... \\
Quando... \\
Como... \\
Referenncias \\
\end{tabular} & \multicolumn{2}{|c|}{$\begin{array}{l}\text { Como... } \\
\text { Procedimentos } \\
\text { Algumas orientações para execução das atividades do simple Way Process... }\end{array}$} \\
\hline \multirow[t]{7}{*}{ Edt sidebar } & Atividade & Orientações para execução da atividade \\
\hline & Definição do escopo & Conversar com o cliente para entender o sistema \\
\hline & Construção do escopo & Segundo artefato proposto pelo processo \\
\hline & Geração do orçamento do projeto & Segundo artefato proposto pelo processo \\
\hline & Validação do escopo & Acompanhar o cliente na validação do documento de escopo \\
\hline & Assinatura do escopo & Assinar artefato proposto pelo processo \\
\hline & Assinatura de proposta comercial & Assinar artefato proposto pelo processo \\
\hline
\end{tabular}

Figura 7 - Ambiente do SWP - Página "Como..." - Subpágina Procedimentos

A Figura 8 trata da página que contém os templates de artefatos sugeridos para o SWP, destacando-se o fato de que a mesma apresenta um link de navegação para a página "Procedimentos", o que permite ao usuário consultar as informações referentes ao uso dos templates no processo. 


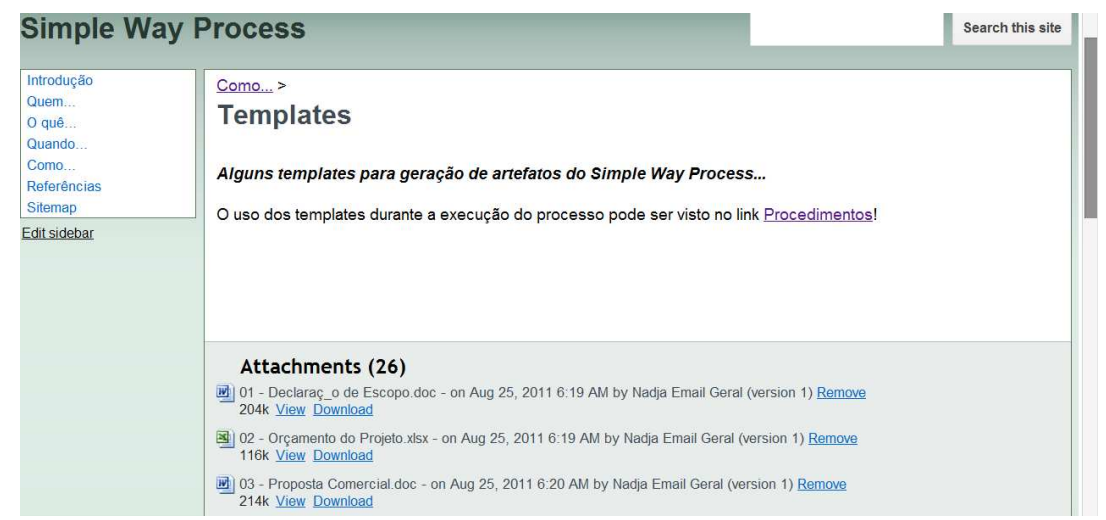

Figura 8 - Ambiente do SWP - Página "Como..." - Subpágina Templates

A Figura 9 mostra as ferramentas sugeridas para o SWP. A coluna de disciplinas relacionadas apresenta links para as páginas das disciplinas do processo. Algumas ferramentas apresentam links para páginas oficiais das ferramentas na web.

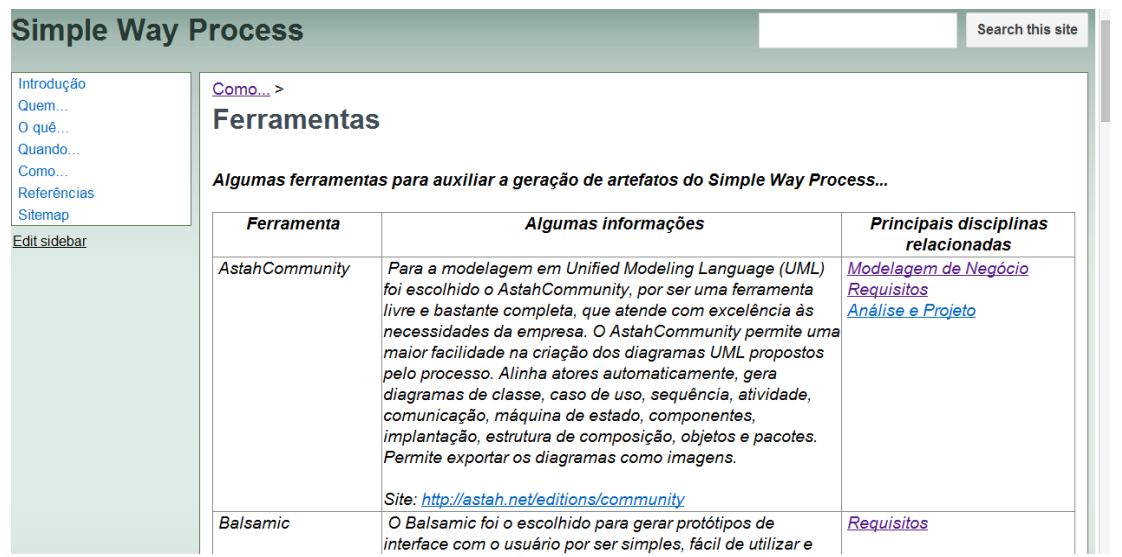

Figura 9 - Ambiente do SWP - Página "Como..." - Subpágina Ferramentas

\section{Relato de Experiência}

O SWP começou a ser esboçado em 2010, tendo sido concluído no início de 2011. Desde as suas primeiras sugestões de atividades, papéis e artefatos, este PDS vem sendo utilizado tanto pela empresa júnior como nas aulas de engenharia de software aplicada.

Sobre o uso do SWP na empresa júnior, pode-se dizer que este trouxe mais sistematização às rotinas organizacionais técnicas, garantindo mais agilidade as suas atividades e maior qualidade aos seus produtos. O trabalho técnico da empresa, antes apoiado pelo XP1 e ajustado com dificuldade (especialmente pela carência de templates adequados e pela falta de padronização de ferramentas e procedimentos), passou a ser guiado pelo SWP, tendo à sua disposição todos os elementos necessários para a execução de cada uma das atividades do projeto. Após a implantação do SWP, tornou-se mais simples a distribuição da equipe nos seus respectivos papéis (cada aluno, dependendo da sua maturidade no curso, pôde ser alocado em um papel adequado).

Com o uso do XP1, era difícil absorver alunos dos períodos iniciais do curso, em virtude das habilidades técnicas exigidas pelos papéis deste processo. Pela maior diversidade e adequação de papéis à realidade da empresa júnior, atualmente podem ser 
admitidos pela empresa alunos desde o período inicial do curso. Ainda tornaram-se mais adequadas e claras as atividades do processo, o relacionamento entre elas, suas entradas, saídas e orientações em geral. Essas melhorias também se refletiram nos clientes, que passaram a perceber documentos e ações padronizados e um maior nível de organização da empresa. Um dos indicadores do alcance do uso do SWP é o número de projetos reais (da empresa júnior) gerados através do SWP: 03 projetos. Outro indicador diz respeito ao número de alunos integrantes da empresa que utilizaram o SWP para a geração dos seus projetos: 22 alunos. Atualmente, a empresa conta com 12 alunos.

Com relação à aplicação do PDS e do seu ambiente em sala de aula, serão relatados os principais pontos observados. A disciplina de engenharia de software aplicada (chamada PDS, na IES considerada) é obrigatória e pertence ao $4^{\circ}$ período (o curso tem o total de seis períodos), sendo lecionada semestralmente. Nesta os alunos podem ter a visão geral de todo o processo relacionado ao desenvolvimento de software, sob a ótica de vários modelos propostos pela indústria. Considera-se que esta visão é importante para que o aluno desenvolva sua visão crítica sobre a aplicação de PDS diferentes (inclusive adaptados), em diversos cenários de produção de software.

Inicialmente, esta disciplina era lecionada apresentando processos como RUP e XP, sendo escolhido o RUP para as aulas em oficina de projetos, uma vez que várias práticas do XP não poderiam ser utilizadas, especialmente em decorrência da dificuldade de os alunos trabalharem em duplas fora de sala de aula. Uma vez que o RUP possui um grande número de papéis, atividades e artefatos gerados, alguns deles eram escolhidos para ser executados na oficina. Os projetos eram fictícios e desenvolvidos em grupos de três ou quatro alunos. Com a definição do SWP e a criação do seu ambiente, alguns aspectos metodológicos da disciplina sofreram mudanças. Os alunos continuam tendo a visão inicial dos PDS da indústria, sendo somados ao RUP e $\mathrm{XP}$, o Scrum e o PMBok. Ainda são comentados alguns modelos acadêmicos, como o YP e o XP1. Ao invés de os projetos da oficina instanciarem o RUP, eles fazem uso do SWP e do seu ambiente. Uma vez que a professora de PDS é também consultora da empresa, alguns projetos na disciplina são projetos ou subprojetos reais desta empresa.

$\mathrm{Na}$ execução dos projetos, os alunos que fazem parte da empresa júnior podem usar o seu tempo na disciplina para desenvolver os projetos reais da empresa e assim aplicar de fato os conceitos de engenharia de software na prática em projetos. Da turma atual de PDS, $40 \%$ pertencem à empresa júnior. Os alunos que dela não fazem parte, por sua vez, podem imergir temporariamente na mesma e sentir como é a rotina de trabalho em uma empresa de desenvolvimento de software. Inclusive, alguns deles se sentem motivados a participar do processo de seleção da empresa, depois de viverem essa experiência na disciplina. No caso de serem absorvidos pela empresa, a curva de aprendizado no SWP e no seu ambiente é mínima, uma vez que já foram "capacitados" através da disciplina de engenharia de software aplicada. 33\% dos integrantes atuais da empresa júnior relataram que desejaram participar do processo seletivo após as discussões sobre a empresa júnior nas aulas de engenharia de software.

A ideia associada à disciplina é que os alunos desenvolvam os projetos em grupo, desde que seja respeitado o rodízio entre os papéis, atividades e artefatos do SWP, para que cada um deles possa conhecer o processo como um todo e se familiarizar com as diversas etapas da construção de um software. Um indicador do SWP referente à 
disciplina engenharia de software aplicada é o número de alunos da disciplina PDS de que utilizaram o SWP e o seu ambiente em sala de aula: 28 alunos.

Os alunos da disciplina Estágio Supervisionado também estão fazendo uso do SWP e do seu ambiente. A idéia de aplicar o SWP e o seu ambiente no estágio surgiu pelo fato de a professora de PDS ser a professora orientadora dos estágios, e pelo fato de que, por interesse dos próprios alunos, todos os estágios estão sendo realizados na empresa júnior. Uma vez que o SWP é guiado por requisitos e considerando que os alunos no estágio supervisionado estão no último período do curso, durante o estágio, esses alunos recebem parte do escopo de um projeto real (que pode ser da empresa júnior ou não) e devem passar por todas as disciplinas técnicas do SWP (Modelagem de Negócio, Requisitos, Análise e Projeto, Implementação, Testes e Implantação). Ou seja, durante o estágio, o aluno também tem a experiência de participar das diversas etapas da construção de um software. Para as demais disciplinas do SWP, valem as seguintes regras: a Gerência de Projetos deve ser executada, preferencialmente, por apenas um dos estagiários do projeto, que por ter um grande esforço nas atividades de gerência, recebe um menor número de requisitos do projeto (ou requisitos de menor complexidade) para desenvolver no estágio; as demais disciplinas (Gerência de Mudanças e Ambiente), por requererem esforços eventuais, têm esses esforços diluídos entre os estagiários, de acordo com a necessidade. Toda a execução do estágio é supervisionada pela professora orientadora de estágio. Um indicador do SWP é o número de alunos que realizaram o estágio e produziram projetos reais através do SWP: 08 alunos (alocados em 2 projetos).

Ao longo de sua utilização por diferentes alunos, o SWP e o ambiente vêm sendo criticamente analisados, tendo sido criado um repositório de sugestões para melhoria de ambos. Está prevista uma nova versão do SWP e do ambiente para abril de 2012.

\section{Considerações Finais}

Uma proposta para ensino e aprendizagem de engenharia de software aplicada foi apresentada neste trabalho. O objetivo é sugerir que sejam instanciados em sala de aula modelos de PDS adaptados de acordo com as características de cada IES, e que sejam criados ambientes que suportem esses processos, orientando os alunos na execução de projetos. A idéia é tornar viável o desenvolvimento de projetos (reais ou fíctícios) durante o tempo de execução das disciplinas relacionadas à engenharia de software, e aproximar academia e indústria, trazendo aos alunos a oportunidade de desenvolver as boas práticas desta área.

Uma vez que a IES tratada neste trabalho possui uma empresa júnior ligada ao curso de Análise e Desenvolvimento de Sistemas, e considerando que o trabalho na empresa respeita as restrições dos alunos em ambiente acadêmico para execução de projetos de software, utilizou-se o PDS desta empresa, o SWP, e o seu ambiente, para a prática de engenharia de software através das disciplinas Processos de Desenvolvimento de Software e Estágio Supervisionado. A estrutura do SWP e a metodologia aplicada nas disciplinas favorecem a prática da engenharia de software, a partir do momento em que fazem com que os alunos executem o rodízio entre os papéis, atividades e artefatos do SWP, e assim possam ter contado com os elementos imprescindíveis aos PDS.

A experiência de ensino e aprendizagem de engenharia de software através do uso do SWP pode ser vista sob a ótica de seus benefícios multilaterais: os alunos se 
beneficiam através do contato com as rotinas de uma empresa de desenvolvimento de sistemas, executando projetos de software de acordo com as boas práticas da indústria; a empresa júnior se beneficia através do refinamento do SWP e do ambiente, a partir das sugestões dos alunos que utilizam ambos, e através da capacitação de futuros membros (oriundos da experiência nas disciplinas); pode-se chegar a pensar nos benefícios para a indústria, que tem à sua disposição profissionais com bagagem teórica e prática, e capacidade de fazer análises críticas sobre questões ligadas à construção de software.

Como trabalho futuro, espera-se executar o refinamento do SWP e do seu ambiente, através das diversas contribuições dadas como sugestões de melhoria, e da implantação de novas versões destes ainda no primeiro semestre de 2012. Avalia-se ainda a possibilidade de usar o SWP e seu ambiente em outras disciplinas do curso, de forma que os alunos possam entender o contexto de cada disciplina, e dos seus respectivos relacionamentos, com o processo de construção de software. Para este fim, espera-se contar com um grupo de professores e alunos que possam trabalhar de forma integrada na idealização do uso do SWP, tanto no cenário academia, para aulas diversas, como no cenário indústria, no dia a dia da empresa júnior.

\section{Referências}

AM (2011). Agile Modeling. http://www.agilemodeling.com. Janeiro.

Durscki, R. C. et al. (2004). "A Development Process to Technology Projects: An Academic Approach", The 2004 International Conference on Software Engineering Research and Practice, Track on Team-based Software Engineering, USA.

Garcia, F. P. et al (2004). "eas YProcess: Um Processo de Desenvolvimento para Uso no Ambiente Acadêmico". XII WEI - Workshop de Educação em Computação, XXIV Congresso da Sociedade Brasileira de Computação.

Paiva, D. M. B et al (2004). "Definindo, Implantando e Melhorando Processos de Software em Ambiente Acadêmico". VI Simpósio Internacional de Melhoria de Processos de Software. http://www.simpros.com.br/Apresentacoes_PDF/Artigos/Art_07_Simpros2004.pdf.

Paula Filho, W. P. (2002). "An Educational Software Development Process" Proceedings of the ACIS International Conference on Computer Science, Software Engineering, Information Technology, EBusiness and Applications (CSITeA'02), p.180-185.

PMBok (2004). PMBoK GUIDE - Project Management Body of Knowledge.

Pressmam, R. S. (2006). Engenharia de Software. 6 ed. São Paulo: McGraw-Hill.

RUP (2011). Rational Unified Process. http://www.wthreex.com/rup/portugues/index.htm. Janeiro.

Scrum (2011). Scrum Alliance. http://www.scrumalliance.org/. Janeiro.

Sommerville, Ian. (2007). Engenharia de Software. 8 ed. São Paulo: Pearson Addison-Wesley.

Teles, V. M. (2006), Extreme Programming: aprenda como encantar seus usuários desenvolvendo software com alta qualidade. São Paulo: Novatec.

UPEDU (2011). Unified Process for EDUcation. http:// http://www.upedu.org/. Fevereiro.

XP (2011). eXtreme Programming. http://www.extremeprogramming.org. Janeiro.

XP1 (2007). "XP1: Um Processo de Desenvolvimento". http://dsc.ufcg.edu.br/ jacques/projetos/common/xp1/xp1.html. Março.

YP (2011). easYProcess. http://www.dsc.ufcg.edu.br/ yp. Janeiro. 